\title{
Visiones de los vencidos. Memorias divergentes y heterogéneas
}

Visions of the vanquished. Heterogeneous and divergent memories

\author{
Carlos García-Bedoya Maguiña \\ Universidad Nacional Mayor de San Marcos, Lima, Perú \\ Contacto: cgarciabedoyam@unmsm.edu.pe \\ http://orcid.org/0000-0002-1543-662X
}

\section{Resumen}

En este trabajo se examinan dos textos que representan los divergentes puntos de vista de los sectores de la élite Inca ante la conquista española: la llamada Relación de los Quipucamayos, compilada inicialmente en 1542, y la Instrucción de Titu Cusi, redactada en 1570. El primero expresa el punto de vista del sector de la élite incaica que optó por insertarse en el nuevo orden establecido por los vencedores, y destaca los servicios prestados por el inca Paullu y los méritos de sus descendientes. El segundo formula el punto de vista del sector que optó por la resistencia, pero también por la negociación, y resalta la figura de Manco Inca y sus sucesores, quienes lideraron hasta 1572 el llamado estado neoinca de Vilcabamba. El análisis de los textos se centrará en la construcción discursiva de estas memorias divergentes de los "vencidos" en el proceso de imposición del dominio colonial.

Palabras clave: Crónicas indígenas, Conquista del Perú, Incas, Resistencia.

\begin{abstract}
This article studies two texts that represent the divergent perspectives of different factions of the Inca elite towards the Spanish conquest: the Relación de los Quipucamayos, compiled initially in 1542, and Tito Cusi's Instrucción, written in 1570. The former expresses the point of view of the sector that decided to adapt to the new order established by the victorious Spaniards; it exalts the contributions of Inca Paullu and the merits of his descendants. The latter expresses the perspective of the sector that favored the resistance against Spanish conquest, but also negotiation, and exalts Manco Inca and his successors, who ruled until 1572 the so-called Neo Inca state in Vilcabamba. Text analysis will focus on the discursive construction of the divergent memories of those "vanquished" in the process of imposition of colonial domination.
\end{abstract}

Key words: Indigenous chronicles, Conquest of Peru, Incas, Resistance. 
Miguel León-Portilla (Visión de los vencidos: relaciones indígenas de la conquista, 1959) primero, y Nathan Wachtel (La vision des vaincus. Les indiens du Pérou devant la conquête espagnole, 1971), después, nos presentaron la visión de los vencidos durante el proceso de la conquista o invasión española (en el caso mexicano, el primero; en el peruano, el segundo). El enfoque tendía a sugerir que los discursos de los vencidos conformaban un corpus homogéneo, signado por la resistencia al invasor español. Sin embargo, es bien sabido que el éxito militar de los conquistadores hubiera sido imposible sin la colaboración activa y decisiva de etnias y élites indígenas, como lo evidencian tanto el caso mexicano como el peruano. Resulta entonces claro que el discurso de los vencidos es plural y heterogéneo, y que construye memorias divergentes, cuando no francamente contradictorias.

En el caso de la conquista del Tawantinsuyo, las huestes pizarristas contaron con la colaboración de diversas etnias descontentas, pero también aprovecharon en su favor las pugnas entre los dos pretendientes a la mascaypacha o corona inca: Huáscar y Atahualpa, expresión de los conflictos entre las distintas panacas o linajes de la nobleza incaica. En el presente trabajo se abordarán dos textos que representan estos divergentes puntos de vista: la llamada Relación de los Quipucamayos, compilada inicialmente en 1542, y la Instrucción de Titu Cusi, redactada en 1570. El primero expresa el punto de vista del sector de la élite incaica que optó por insertarse en el nuevo orden establecido por los vencedores, y destaca los servicios prestados por el inca Paullu y los méritos de sus descendientes. El segundo formula el punto de vista del sector que optó por la resistencia, pero también por la negociación, y resalta la figura de Manco Inca y sus sucesores, quienes lideraron hasta 1572 el llamado estado neoinca de Vilcabamba. El análisis de los textos se centrará en la construcción discursiva de estas memorias divergentes de los "vencidos" en el proceso de imposición del dominio colonial.

$$
\text { -II- }
$$

La invasión española (lo que tradicionalmente se llamaba la conquista) significó sin duda el quiebre más drástico en el proceso histórico peruano. Sin embargo, la imposición de este dominio colonial no fue un simple proceso militar, sino una 
operación de naturaleza mucho más compleja. En efecto, supuso ante todo la desestructuración de las esferas del poder, de la producción y de la cultura vigentes en el Imperio inca.

La fase propiamente militar de la conquista duró solo cinco años y llegó a su fin en 1537. Su momento álgido se produjo cuando Manco Inca, el soberano títere impuesto por los invasores, impulsó una gran rebelión que hizo peligrar los éxitos españoles. En 1537, Manco Inca se vio forzado a replegarse a Vilcabamba, un reducto casi inaccesible en el Antisuyo. Allí subsistió por más de treinta años un pequeño Estado inca. Era un foco de resistencia bastante aislado y ubicado en la periferia, por lo que su capacidad para desafiar al poder español fue escasa. Sin embargo, fue una amenaza latente y aun pudo fomentar movimientos de resistencia social y cultural como el Taki Onqoy. Finalmente, el virrey Toledo emprendió la erradicación de ese baluarte de la disidencia y, en un acto espectacular y simbólico, hizo decapitar en 1572 al último Inca de Vilcabamba, Túpac Amaru, cerrando así el denominado periodo de imposición del dominio colonial.

El impacto brutal de la invasión española y la imposición agresiva de los paradigmas culturales occidentales tuvieron consecuencias devastadoras sobre los sistemas literario-discursivos de los vencidos. Aquellos ligados a las élites sociales, tanto de nivel imperial como de nivel local, sufrieron un proceso de acelerada desarticulación. Si bien es cierto que los sistemas literario-discursivos procedentes de la época prehispánica no colapsaron repentinamente, su suerte estaba echada. La tecnología de la escritura importada de occidente permitió preservar de manera frecuentemente fragmentaria y distorsionada algunos remanentes de la tradición prehispánica, gracias ante todo a la labor de los cronistas. Aquellos sistemas ligados a los grupos subalternos resistieron mejor el impacto de la invasión. Replegados en una posición de resistencia, pudieron incorporar algunos aportes de la más sofisticada tradición de las élites, y sufrieron el progresivo impacto de la nueva cultura dominante, dándose inicio a los enrevesados procesos de transculturación que irán configurando los rasgos duraderos de las literaturas orales andinas populares. Paulatinamente, los vencidos, en especial las élites o aristocracias andinas, produjeron o promovieron la elaboración de una serie de 
documentos y textos que, desde una cosmovisión andina, representaron su punto de vista ante la irrupción de la nueva cultura dominante y la destrucción de las estructuras sociales del Tawantinsuyo.

Los dos documentos que luego serán examinados constituyen muestras representativas de estas tempranas textualidades andinas. Cabe incluir a ambas obras en el ámbito de lo que Martin Lienhard denomina crónicas mestizas, es decir, "aquellas crónicas que, casi independientemente del origen étnico de sus autores (indígenas, mestizos, españoles), reelaboran materiales discursivos o reales de la historia americana a través de unos procedimientos narrativos (verbales y/o pictográficos) de tradición heterogénea: indígena y europea” (1983, p. 105). Apunta además Lienhard que

Las crónicas mestizas, nacidas a raíz del dominio europeo impuesto brutalmente a las masas indígenas, señalan con meridiana claridad en todos sus elementos híbridos y contradictorios (fabricación, difusión, referente, exposición, trabajo verbal, visiones del mundo subyacentes), las contradicciones culturales e ideológicas del mundo que provoca su surgimiento. (1983, p. 108)

Las propias definiciones de Lienhard permiten inscribir a tales manifestaciones discursivas en el ámbito de las literaturas heterogéneas que estudió Antonio Cornejo Polar $(1978,1994)$. En otro lugar he estudiado las obras más representativas de esta cronística mestiza (he optado también por denominarlas crónicas andinas transculturales) en el periodo de estabilización colonial (García-Bedoya, 2000, p. 171-195).

\section{-III-}

Pasaré ahora a examinar el texto citado frecuentemente como Relación de los Quipucamayos, cuyo manuscrito se conserva en la Biblioteca Nacional de Madrid, y que fue publicado por primera vez en 1892 por Jiménez de la Espada bajo el título Una antigualla peruana. En 1921 lo reeditó Horacio Urteaga con el título de "Discurso sobre la descendencia y gobierno de los Incas". La edición más 
asequible es la publicada en 1974 por Juan José Vega con el título de Relación de la descendencia, gobierno y conquista de los Incas; Vega señala en la portada a Collapiña (sic., en el texto mismo se le denomina Callapiña), Supno y otros quipucamayos como los autores de esta obra.

Se trata de un texto que plantea serios problemas filológicos que aquí apenas cabe rozar. La redacción final del texto corresponde a un misterioso Fray Antonio, a quien Porras propuso identificar como fray Antonio Martínez. Fray Antonio sería responsable de la redacción global de la versión que hoy conocemos, lo que implicaría uniformizar el estilo de materiales textuales heterogéneos y añadir diversas interpolaciones. Fray Antonio firma su texto el 11 de marzo de 1608, remitiéndolo a las autoridades españolas. Sin embargo, la primera parte del texto, que es propiamente la Relación de los Quipucamayos, habría sido redactada en 1542 por orden del gobernador Vaca de Castro. En su elaboración participaron como informantes cuatro quipucamayos (depositarios de la tradición oral y expertos en el manejo del sistema de información de los quipus) procedentes de Pacaritambo, el mítico lugar de origen o pacarina de los Incas, de dos de los cuales se conserva el nombre: los mencionados Callapiña y Supno. Como traductor participó el indio ladino Pedro de Escalante, contando con la colaboración de dos españoles conocedores de la lengua quechua: Francisco de Villacastín y el renombrado cronista Juan de Betanzos; los dos últimos, además de supervisar la traducción, debieron encargarse principalmente de la redacción castellana de los materiales. Diversas crónicas, entre ellas los Comentarios reales del Inca Garcilaso, confirman que Vaca de Castro mandó recopilar ese tipo de información. Franklin Pease, sin embargo, considera que la versión incluida en el texto compilado en 1608 por Fray Antonio es probablemente una versión resumida de la información recopilada en 1542, y que habría sufrido además diversas interpolaciones y distorsiones (Pease, 1995, p. 23).

Más allá de tales problemas filológicos, es claro que la Relación de los Quipucamayos consta de dos partes claramente diferenciadas. La primera, basada en el relato de los quipucamayos, refiere la historia de los Incas, incidiendo en su origen, la sucesión y las conquistas de los diversos soberanos. El relato sigue el 
orden dinástico de los Incas, presentando una lista de 12 Incas o Capaccuna coincidente con las versiones más aceptadas, en cuanto al orden y el nombre de los soberanos, lo que en opinión de Pease podría implicar ciertas modificaciones tardías a la versión originalmente compilada en 1542 (Pease, 1995, p. 68). Esta primera parte lleva claras huellas de formas discursivas andinas. José Antonio Mazzotti ha destacado la presencia frecuente de recursos formulaicos, sobre todo en el relato de las vidas de los Incas (1996, p. 68). A su vez, Galen Brokaw ha resaltado cómo el ordenamiento de esas biografías sigue un patrón fijo que se apoyaría en la estructura informativa del sistema de los quipus. Afirma Brokaw que el texto

[...] presents the history of the Inca empire by sketching the biographies of each individual ruler. These biographies exhibit a highly formulaic structure that is consistent throughout $[\ldots]$ a format that characterizes the presentation of all twelve Inca rulers: (1) the Inca is presented as the successor to his father; (2) military conquests and the area that he governed; (3) the Inca's spouse; (4) the oldest male child; (5) the younger children and the ayllu of their descendants; and (6) the number of years during which the Inca reigned. $(2003, \text { p. 129) })^{1}$

Es importante resaltar las notorias coincidencias entre la versión de la historia incaica planteada en la Relación de los Quipucamayos y la propuesta por el Inca Garcilaso en sus Comentarios reales ${ }^{2}$. En efecto, son estos dos textos los únicos que atribuyen un protagonismo decisivo al Inca Viracocha (o Viracocha Inca) en la expansión y organización del Incario, y no a Pachacutec, como ocurre en las versiones proporcionadas por la mayoría de cronistas. Además de exaltar a Viracocha, se pretende menoscabar a Pachacutec, responsabilizándolo por la introducción de algunos aspectos de la religiosidad indígena especialmente repulsivos para la sensibilidad católica, pues habría sido "el primero que inventó sacrificios al Sol de criaturas e niños e mujeres y doncellas y mozuelos de ocho o diez años [...] Ansímesmo fué el primero que comenzó a tomar las hermanas por concuminas [concubinas]" (Vega, 1974, p. 57). Esto revela que las fuentes incas que nutrieron ambas obras proceden de sectores de la élite adversos a la panaca de 
Pachacutec, por lo que construyeron una versión que disminuyó el rol histórico de dicho Inca, pues estaban más bien vinculados a la panaca de Tupac Yupanqui (a la que pertenecía la madre de Garcilaso). Coinciden por ello también ambas obras en su firme rechazo a Atahualpa, patrocinado por la panaca de Pachacutec, y a quien consideran bastardo y usurpador, en tanto afirman la condición de heredero legítimo de Huáscar, quien contó con el respaldo de las demás panacas, en especial la de Tupac Yupanqui, cuyos integrantes fueron diezmados por los generales de Atahualpa. Se aprecia claramente cómo distintas facciones de la élite incaica proponían versiones divergentes y contradictorias de su pasado, reconstruyéndolo desde sus filias y sus fobias, en función de intereses muy concretos: la lucha por el poder era muy descarnadamente una lucha por el control de la memoria ${ }^{3}$.

La segunda parte de la obra, redactada probablemente por Fray Antonio, tiene la estructura básica de una probanza de servicios del Inca Paullu; su redacción fue seguramente encargada por sus descendientes, con miras a obtener muy concretos beneficios. El propio Inca Garcilaso alude a estas gestiones bastante exitosas: nos informa de la posición privilegiada de que gozaba Melchor Carlos Inca, nieto de Paullu, en la corte española. También hace referencia al egoísmo de ese personaje, que buscaba presentarse como único superviviente del linaje inca. En el último capítulo de la segunda parte de sus Comentarios reales (también conocida como Historia general del Perú), explica cómo los representantes de las distintas panacas de la nobleza inca cuzqueña enviaron un memorial a la corte demandando el reconocimiento de los privilegios correspondientes a su estirpe aristocrática; asimismo, cómo Melchor Carlos Inca, en lugar de favorecerlos en esa gestión, ocultó el memorial para hacerse único acreedor a las mercedes otorgadas por la corona a los descendientes de los Incas.

Por ello, resultaba esencial en la segunda parte del texto exaltar la figura de Paullu Inca. Para retomar un planteamiento de Martin Lienhard (aunque este autor no aplica el concepto al texto que se está abordando), esta segunda parte se articula — según el modelo del homenaje ritual al Inca (Lienhard, 1992, pp. 146166) - , como un intento de cantar épico que refiere las hazañas de Paullu. Se destaca, ante todo, su actuación decisiva en la derrota de la sublevación de Manco 
Inca. En el texto se señala a Huáscar como único hijo legítimo, y por tanto heredero de Huayna Capac, aplicando categorías mentales españolas que no funcionaban, como se sabe, en el mundo andino, pero que se utilizaban para adecuarse a los paradigmas discursivos del dominador. El texto reconoce por ello que tanto Manco Inca como Paullu eran hijos ilegítimos, aunque se intenta deslizar que Paullu procedía de linaje más encumbrado que Manco Inca. Esta segunda parte del texto representa pues la perspectiva del sector de la nobleza Inca que optó por la colaboración con los españoles, no por la resistencia, de allí que toda esta parte se estructure con base en la oposición de las dos figuras emblemáticas que encarnan estas opciones contrapuestas. Se destaca por ello el rol de Paullu, quien lidera vastos contingentes indígenas que posibilitan la derrota de las huestes de Manco Inca. Se atribuye incluso a Francisco Pizarro el arrepentirse de no haber entregado la borla o mascaypacha inca al servicial Paullu en lugar de al díscolo Manco Inca:

\begin{abstract}
El marqués don Francisco Pissarro y el adelantado don Diego de Almagro, visto el valor y autoridad de tan gran señor, no dejaron de mostrar sentimiento por haber dado la borla y el señorío a Manco Inca. A Paullo Topa Inga toda la tierra de indios le servía con mucho amor y voluntad y respecto. (Vega 1974, p. 57)
\end{abstract}

A la invalorable ayuda prestada por Paullu a los españoles habría que agregar como uno de sus méritos mayores el haber sido el primer Inca bautizado. Buen cristiano, vasallo leal, Paullu merecía la gratitud de la corona española. Él y sus descendientes disfrutaron de las mercedes correspondientes a tan señalados servicios. Tal es, al menos, la versión que se presenta aquí. Para concluir, se aprecia pues que la estrategia discursiva en esta segunda parte del texto apunta a construir una versión del pasado desde la mirada de quienes optaron por la colaboración con los vencedores.

\title{
-IV-
}

En contraste, la Instrucción de Titu Cusi presenta la visión de quienes optaron por la resistencia contra los invasores españoles. A diferencia también de la $R e$ - 
lación de los Quipucamayos, se trata de un texto que ha gozado de una difusión mucho mayor y que ha merecido también amplia atención de los investigadores. El manuscrito, fechado en 1570, se encuentra en la Biblioteca del Escorial. Fue publicado por primera vez en 1916 por Horacio H. Urteaga y Carlos A. Romero. Ha sido reeditado luego, con títulos diversos, por Francisco Carrillo (1973), Luis Millones (1985), María del Carmen Martín Rubio (1988) y Liliana Regalado de Hurtado (1992). Ha merecido, además, traducciones al alemán (Martin Lienhard, 1985) y al inglés (Nicole Delia Legnani, 2005; Ralph Bauer, 2005; Catherine Julien, 2006).

El texto que hoy se lee es fruto de una superposición de $\operatorname{voces}^{4}$, que en varios niveles le dan una textura polifónica, en el sentido bajtiniano del concepto. Sin duda, la voz principal es la del propio Titu Cusi Yupanqui, sucesor de Sayri Tupac y predecesor de Tupac Amaru (sus hermanos ambos) en el trono de Vilcabamba, aunque él se proclama sucesor inmediato de su padre Manco Inca, designado heredero por el propio soberano moribundo. El discurso de Titu Cusi se emitió oralmente en quechua, en tanto la redacción final en castellano se debe a la intervención del agustino español fray Marcos García y del escribano mestizo Martín de Pando. Además, participaron como testigos otro fraile agustino, Diego Ortiz, y tres capitanes incas: Suta Yupangui, Rimache Yupangui y Sullca Varac. Para dar plena validez jurídica al documento, el 6 de febrero de 1570 lo firmó el propio Inca, al igual que los dos frailes en calidad de testigos, dando fe de todo el escribano mestizo, como correspondía a su función.

A través de la intervención de estos diversos sujetos se configura, pues, un tejido inextricable entre la oralidad andina y la escritura hispánica, entre la perspectiva señorial del Inca, la mirada del religioso español y la visión de un mestizo bicultural. De este modo, el texto resulta una expresión temprana de transculturación discursiva. Las huellas de la oralidad se evidencian claramente en el constante uso del discurso directo que, además de responder a una estrategia retórica de “dramatización" de las distintas voces, en especial la de Manco Inca, es también resultado de los procedimientos lingüísticos característicos del quechua.

El propio sujeto principal de la enunciación, Titu Cusi, es un escindido su- 
jeto heterogéneo ${ }^{5}$. Si bien su mundo cultural es básicamente andino-inca, cabe recordar que durante su infancia fue raptado y pasó algunos años en el Cuzco con una familia española, los Oñate, lo que debió significar alguna familiaridad con elementos culturales hispánicos. A ello hay que agregar que, años más tarde, ya adulto, fue adoctrinado y finalmente bautizado por los frailes agustinos. A esa heterogeneidad constitutiva del propio sujeto Titu Cusi hay que agregar la contribución de los otros sujetos que participaron en el proceso de producción textual, en particular el fraile Marcos García; a este se debe la fuerte presencia de una retórica cristiana en la que posiblemente se deslizan ecos lascasianos, sin olvidar los aportes del mestizo Pando, que tenía sin duda su propia agenda.

La heterogeneidad del texto y de los sujetos productores tiene un último correlato en la de los destinatarios. Así, de un lado se tiene a las autoridades coloniales e imperiales españolas, desde el propio Lope García de Castro, a quien Titu Cusi le da sus "instrucciones", hasta el mismo rey Felipe II, a quien en última instancia el Inca expone sus méritos y demanda mercedes; cabe apuntar que esta presencia del rey de España como interlocutor privilegiado asemeja este texto al de Guaman Poma, que es, como bien se sabe, una larguísima carta al monarca ibérico. Por otro lado están las élites indígenas que podían tener algún acceso al discurso letrado, así como algunos mestizos en quienes podía calar este discurso disidente, abiertamente cuestionador del orden colonial ${ }^{6}$.

Curiosamente, este texto híbrido o heterogéneo, que en un nivel enuncia el cantar de gesta de la resistencia inca, incluye sin embargo otra dimensión, muy vinculada a los marcos del discurso jurídico español de la época: es también una probanza de servicios y una solicitud de mercedes del propio Titu Cusi, al mismo tiempo que el acto legal mediante el cual este da poder al Gobernador del Perú, Lope García de Castro, para hacer gestiones a favor de sus intereses personales. Entonces, a nivel discursivo hay una estrategia de confrontación y de negociación. En el plano de la negociación, el segmento final del documento concede amplio poder a Lope García de Castro para hacer cualquier gestión en beneficio de Titu Cusi ante el rey de España. El objetivo es, pues, en este caso, similar al de los descendientes de Paullu: obtener beneficios personales (o familiares) 
muy concretos. Para ello, insiste Titu Cusi en su condición de señor natural del Perú, en tanto hijo legítimo, primero y mayorazgo, de Manco Inca, al que a su vez proclama heredero legítimo de Huayna Capac. Para consolidar su estrategia retórica se vale de la terminología al uso en los modos discursivos apropiados del mundo hispánico, seguramente bien asesorado por el fraile agustino y por el escribano mestizo. Recalca, además, su condición de católico debidamente bautizado. Todo ello consolida, en el marco negociador, sus pretensiones al favor real. Esta estrategia entronca perfectamente con las negociaciones llevadas a cabo por Sayri Tupac, que culminaron con su sumisión ante el virrey Andrés Hurtado de Mendoza y su establecimiento en el Cuzco (en su Instrucción, Titu Cusi pretende que su hermano era meramente su emisario). Las negociaciones continuaron con el virrey Conde de Nieva, prosiguieron mediante conversaciones con el licenciado Matienzo, luego con la llegada a Vilcabamba de los frailes agustinos y culminaron con la Instrucción al gobernador Lope García de Castro. La estrategia negociadora del Estado neoinca de Vilcabamba solo llegará a su final repentino con la decisión del virrey Toledo de extirpar ese foco de resistencia con la captura y posterior ejecución de Tupac Amaru en 1572. Esa decisión drástica obedeció seguramente a la otra faceta de la política de los Incas de Vilcabamba: la resistencia, tanto simbólica - mediante la persistencia de un Estado que, aunque pequeño y marginal, era heredero del Tawantinsuyo y por tanto un modelo alternativo para la población indígena frente al caos colonial—, como también por la resistencia más activa - a través de ocasionales escaramuzas fronterizas y quizá, en especial, su impacto en el desarrollo del movimiento nativista mesiánico del Taki Onqoy_ ${ }^{7}$.

Visto desde el otro ángulo, el de la resistencia, el texto se organiza, tal como lo apuntó Lienhard, como un homenaje ritual al Inca, un cantar épico de las hazañas de Manco Inca. El marco ritual de la ceremonia de homenaje al Inca incluye una dimensión espectacular (cabe hablar de dramatización, siempre y cuando se entienda el término en un sentido muy distinto de la teatralidad occidental), que combina la danza, el canto y la narración oral:

El "espectáculo" o representación dramática surge en medio de un rito que involucra a toda la aristocracia incaica y cuyo marco, como en los ritos andinos 
actuales, es una especie de banquete colectivo con sus comidas, la bebida sagrada (aqa: chicha) y la hoja de coca. La representación [...] combina el canto acompañado de los tambores, narración y danza. (Lienhard, 1992, pp. 151-152)

El aspecto discursivo puede ser entendido como un tipo de cantar de gesta que celebra las hazañas del Inca, al tiempo que sirve para organizar la memoria histórica. El ejemplo más conocido se puede apreciar en la crónica de Betanzos, en la que se ha detectado un subtexto épico que exalta las hazañas del gran constructor del imperio, Pachacutec Inca Yupanqui. Lienhard, desde esta perspectiva, califica a la Instrucción de Titu Cusi como la epopeya de Manco Inca.

En efecto, Manco Inca encarna la figura modélica y ordenadora del mundo andino. Se afirma por ello que tanto Huascar como Atahualpa eran usurpadores "de sangre suez e baxa", mientras que Manco Inca "fue hijo legitimo de sangre real" (Titu Cusi Yupanqui, 1992, p. 6) y, por tanto, señor natural del Incario. Manco Inca, despojado del trono — según Titu Cusi por sus hermanos usurpadores-, acoge con beneplácito a los españoles, a quienes considera como enviados de Viracocha (al que se equipara con la divinidad creadora, según un típico procedimiento retórico del discurso evangelizador). El texto deja en todo momento claramente establecido que no hubo conquista militar por parte de los españoles, de lo que se deriva que estos no pueden argüir ningún derecho de conquista para despojar a la nobleza indígena, en especial al linaje Inca. Ni siquiera en Cajamarca se produjo una victoria militar española, pues los indígenas del séquito de Atahualpa estaban desarmados. Manco Inca acogió con benevolencia a Pizarro y a sus huestes en el Cuzco, creyéndolos enviados de Viracocha. El fracaso de Manco Inca en su posterior ofensiva contra el Cuzco no se debería a razón militar alguna, sino a milagrosas intervenciones sobrenaturales. Desde una concepción providencialista (seguramente contribución de fray Marcos García), esas intervenciones son parte del plan divino para incorporar el mundo andino al ámbito de la cristiandad.

En sus relaciones con los españoles, fue Manco Inca quien encarnó los valores auténticamente cristianos, mientras fueron los españoles quienes los transgredieron constantemente. Manco Inca acogió generosamente a los españoles, respetando tanto los códigos de la reciprocidad andina como los de la caridad 
cristiana (entre los que se establece una implícita correlación). Los españoles, en especial los hermanos de Francisco Pizarro, correspondieron a esa actitud con una prepotencia motivada por la codicia y la lujuria, pecados capitales para la Iglesia católica. Fue esa ingratitud transgresora la que provocó la reacción violenta de Manco Inca, después de múltiples vacilaciones, que motivaron incluso las críticas de sus súbditos. Luego de su fallido ataque al Cuzco, Manco Inca lideró una exitosa campaña de resistencia, que lo constituye en auténtico héroe épico, diestro incluso en el combate a caballo, e invicto militarmente ante las armas españolas. Como buen héroe trágico, muere víctima de algunos españoles, en este caso almagristas, a quienes había acogido con benevolencia y que una vez más le pagaron con traición. Por ello, no sorprenderá el tono amargo de la invocación final a la resistencia que el Inca moribundo dirige a su hijo y heredero, Titu Cusi:

Mira que te mando que perpetuamente nunca tengas ley perfecta con semejante gente que esta, porque no te acontesca a ti otro tanto como a mí. No consientas que entren en tu tierra, aunque mas te conviden con palabras, porque sus palabras melosas me engañaron a mí y ansy harán a ti si los crees. (Titu Cusi Yupanqui, 1992, p. 61)

Todo este relato épico sobre Manco Inca es, por cierto, la expresión de una oralidad de tradición propiamente vilcabambina. En resumen, no se produjo conquista militar, sino una sumisión voluntaria a la corona española: la propuesta final de Titu Cusi Yupanqui implicó ceder los territorios — de los que se consideraba señor natural - al rey Felipe II, a cambio de las mercedes que este debía conceder al heredero de tan insigne linaje. Más allá de esa propuesta de posible integración pacífica al imperio español, el texto formula una recusación demoledora del orden colonial, representado por personajes que encarnan antivalores que implican la negación tanto de la moral cristiana como de los principios andinos de la reciprocidad, instalando un caos social, un desastre que contrasta en el imaginario andino con el ordenado cosmos del incario (Regalado, 1992, en especial pp. XXXVI y XXXIX). 


\section{Notas}

1. "[...] presenta la historia del imperio Inca esbozando las biografías de cada gobernante individual. Estas biografías exhiben una estructura altamente formulaica que es consistente a lo largo del texto [...] un formato que caracteriza la presentación de todos los doce gobernantes Incas: (1) el Inca es presentado como sucesor de su padre; (2) conquistas militares y el área que gobernó; (3) la esposa del Inca; (4) el hijo varón primogénito; (5) los hijos menores y el ayllu de sus descendientes, y (6) el número de años durante los cuales el Inca reinó" (mi traducción). Para un breve balance de la investigación reciente sobre los quipus, véase Beyersdorff (2005).

2. Lo apuntaba ya Mazzotti (1996, pp. 64-65).

3. Lo explica Martin Lienhard: "[...] la historiografía incaica, como toda historiografía dinástica, acostumbraba [...] ofrecer un cuadro expurgado y positivo del pasado"; y añade más adelante: "enfoca los acontecimientos a partir de la perspectiva impuesta por el momento presente y 'rectifica' sin miramientos las incoherencias de la realidad histórica” (Lienhard, 1992, pp. 149 y 157).

4. Este aspecto ha sido examinado por Mazzotti (1996, pp. 85-97).

5. Este aspecto ha sido destacado en No (2005).

6. Este aspecto lo observó acertadamente Chang-Rodríguez (1991, en especial pp. 18-19).

7. Sobre el Taki Onqoy existe una muy amplia bibliografía. El trabajo pionero fue sin duda el de Luis Millones publicado originalmente en 1964 (Millones, 1973). Importante es también el libro editado por el propio Millones (1990). Para un balance más reciente del rico debate sobre este fenómeno, véase Mumford (1998).

\section{Referencias bibliográficas}

Beyersdorff, M. (2005). Writing without Words / Words without Writing. The Culture of the Khipu. Latin American Research Review, 40(3), 294-311.

Brokaw, G. (2003). The Poetics of Khipu Historiography: Felipe Guaman Poma de Ayala's Nueva corónica and the Relación de los quipucamayos. Latin American Research Review, 38(3), 111-147.

Burga, M. (1988). Nacimiento de una utopía. Muerte y resurrección de los Incas. Lima, Perú: Instituto de Apoyo Agrario.

Carrillo Espejo, F. (Ed.). (1991). Cronistas indios y mestizos I. Lima, Perú: Editorial Horizonte. Tomo 6 de la Enciclopedia histórica de la literatura peruana.

Chang-Rodríguez, R. (1991). El discurso disidente. Ensayos de literatura colonial peruana. Lima, Perú: Pontificia Universidad Católica del Perú.

Cornejo Polar, A. (1978). El indigenismo y las literaturas heterogéneas: su doble estatuto socio-cultural. Revista de Crítica Literaria Latinoamericana, 7-8, 7-21.

Cornejo Polar, A. (1994). Escribir en el aire. Ensayo sobre la heterogeneidad socio-cultural en las literaturas andinas. Lima, Perú: Editorial Horizonte. 
García-Bedoya Maguiña, C. (2000). La literatura peruana en el periodo de estabilización colonial. Lima, Perú: Fondo Editorial de la Universidad Nacional Mayor de San Marcos.

Guillén, E. (Ed.). (1974). Versión inca de la conquista. Lima, Perú: Editorial Mi1la Batres.

Hemming, J. (2004). La conquista de los Incas. Ciudad de México, México: Fondo de Cultura Económica.

Jákfalvi-Leiva, S. (1993). De la voz a la escritura: la Relación de Titu Cusi (1570). Revista de Crítica Literaria Latinoamericana, 37, 259-277.

Jiménez de la Espada, M. (Ed.). (1892). Una antigualla peruana. Madrid, España: Tipografía de Manuel Ginés Hernández.

León Portilla, M. (1959). Visión de los vencidos: relaciones indígenas de la conquista. Ciudad de México, México: Universidad Nacional Autónoma de México.

Lienhard, M. (1983). La crónica mestiza en México y el Perú hasta 1620: apuntes para su estudio histórico-literario. Revista de Crítica Literaria Latinoamericana, 17, 105-115.

Lienhard, M. (1992). La voz y su huella. Lima, Perú: Editorial Horizonte.

Lienhard, M. (2008). Indigenous Texts. En J. Pillsbury (Ed.), Guide to documentary sources for Andean studies, 1530-1900 (vol. I, pp. 87-103). Norman, EE. UU.: University of Oklahoma Press.

Mazzotti, J. (1996). Coros mestizos del Inca Garcilaso. Resonancias andinas. Lima, Perú: Bolsa de Valores de Lima, Otorongo Producciones, Fondo de Cultura Económica.

Millones, L. (1973). Un movimiento nativista del siglo XVI: El Taki Onqoy. En J. Ossio (Ed.), Ideología mesiánica del mundo andino (pp. 85-94). Lima, Perú: Ignacio Prado Pastor.

Millones, L. (1980). La religión indígena en la colonia. En F. Silva Santisteban (Ed.), Historia del Perú (tomo V, pp. 421-497). Lima, Perú: Juan Mejía Baca.

Millones, L. (1987). Historia y poder en los Andes centrales: desde los origenes al siglo XVII. Madrid, España: Alianza Editorial.

Millones, L. (1995). Perú colonial. Lima, Perú: Cofide.

Millones, L. (2004). Ser indio en el Perú: la fuerza del pasado. Las poblaciones indígenas del Perú (costa y sierra). Buenos Aires, Argentina: Instituto Di Tella, Siglo XXI Editores de Argentina.

Millones, L. (Ed.). (1990). El retorno de las huacas: Estudios y documentos sobre el Taki Onqoy, siglo XVI. Lima, Perú: Instituto de Estudios Peruanos.

Mumford, J. (1998). The Taki Onqoy and the Andean Nation: Sources and Interpretations. Latin American Research Review, 33(1), 150-165.

No, S. (2005). La heterogeneidad suturada: Titu Cusi Yupanqui. Revista de Crítica Literaria Latinoamericana, 62, 85-96. 
Pease, F. (1995). Las crónicas y los Andes. Lima, Perú: Pontificia Universidad Católica del Perú, Instituto Riva-Agüero, Fondo de Cultura Económica.

Porras Barrenechea, R. (1986). Los cronistas del Perú y otros ensayos. Edición y estudio preliminar de Franklin Pease, bio-bibliografía de Graciela Sánchez Cerro, Félix Álvarez Brun y Oswaldo Holguín Callo. Lima, Perú: Banco de Crédito del Perú.

Regalado de Hurtado, L. (1981). La Relación de Titu Cusi Yupanqui, valor de un testimonio tardío. Histórica, 5(1), 45-61.

Regalado de Hurtado, L. (1992). Estudio preliminar. En Titu Cusi Yupanqui, Instrucción al licenciado Lope García de Castro (pp. IX-LVIII). Lima, Perú: Fondo Editorial de la Pontificia Universidad Católica del Perú.

Regalado de Hurtado, L. (1997). El Inca Titu Cusi Yupanqui y su tiempo: los Incas de Vilcabamba y los primeros cuarenta años del dominio español. Lima, Perú: Fondo Editorial de la Pontificia Universidad Católica del Perú.

Stern, S. (1982). Peru's Indian Peoples and the Challenge of Spanish Conquest: Huamanga to 1640. Madison, EE. UU.: University of Wisconsin Press.

Titu Cusi Yupanqui (1916). Relación de la conquista del Perú y hechos del Inca Manco II. Notas biográficas y concordancias del texto por Horacio $\mathrm{H}$. Urteaga; biografia de Tito Cusi Yupangui por Carlos A. Romero. Lima, Perú: Sanmarti, Colección de libros y documentos referentes a la historia del Perú, tomo 2.

Titu Cusi Yupanqui (1973). Relación de la conquista del Perú. Edición de Francisco Carrillo. Lima, Perú: Ediciones de la Biblioteca Universitaria.

Titu Cusi Yupanqui (1985). Ynstrucción del Inga Don Diego de Castro Titu Cusi Yupanqui. Introducción y edición de Luis Millones. Lima, Perú: Ediciones El Virrey.

Titu Cusi Yupanqui (1988). En el encuentro de dos mundos: los Incas de Vilcabamba: Instrucción del Inca don Diego de Castro Tito Cussi Yupangui 1570. Edición de María del Carmen Martín Rubio; prólogo de Francisco Valcárcel B. Madrid, España: Atlas.

Titu Cusi Yupanqui (1992). Instrucción al licenciado Lope García de Castro. Estudio preliminar y edición de Liliana Regalado de Hurtado. Lima, Perú: Fondo Editorial de la Pontificia Universidad Católica del Perú.

Urteaga, H. (Ed.). (1921). Informaciones sobre el antiguo Perú: (crónicas de 1533 a 1575). Anotaciones y concordancias con las crónicas de Indias de Horacio H. Urteaga. Lima, Perú: Sanmarti, Colección de libros y documentos referentes a la historia del Perú, Segunda serie, tomo 3.

Vega, J. (Ed.). (1974). Relación de la Descendencia, Gobierno y Conquista de los Incas. Lima, Perú: Ediciones de la Biblioteca Universitaria.

Wachtel, N. (1971). La vision des vaincus. Les indiens du Pérou devant la conquête espagnole. París, Francia: Gallimard. 